\title{
A Comparative Immunohistochemical and Quantitative Study of the Epiligament of the Medial Collateral and Anterior Cruciate Ligament in Rat Knee
}

\author{
Estudio Inmunohistoquímico y Cuantitativo del Epiligamento del Ligamento \\ Colateral Medial y Cruzado Anterior en Rodilla de Rata
}

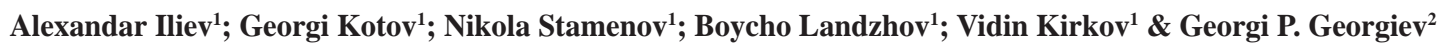

ILIEV, A.; KOTOV, G.; STAMENOV, N.; LANDZHOV, B.; KIRKOV, V. \& GEORGIEV, G. P. A comparative immunohistochemical and quantitative study of the epiligament of the medial collateral and anterior cruciate ligament in rat knee. Int. J. Morphol., 39(1):151159, 2021.

SUMMARY: The aim of the present study was to evaluate the importance of the epiligament for the difference in the healing potential of the knee anterior cruciate and medial collateral ligament. To do so, we compared the structure of the anterior cruciate and the medial collateral ligament and evaluated the differences in the expression of collagen types I, III and V in a rat knee. We have also conducted a comparative quantitative analysis of the number of cells per $\mathrm{mm}^{2}$ in the two ligaments. Tissue samples were obtained from the anterior cruciate and medial collateral ligament of 10 knee joints taken from five 8-month-old Wistar rats. We used standard hematoxylin and eosin staining, in addition to immunohistochemical staining with monoclonal antibodies against collagen types I, III and V. A semi-quantitative analysis of the expression was made through ImageJ, while Student's T-test was used for the statistical analysis. Our results showed higher expression of all collagen types in the epiligament, compared to the ligament proper and difference in the expression between the medial collateral and the anterior cruciate ligament in favor of the first. We also reported a statistically significant difference in the number of cells per $\mathrm{mm}^{2}$ between the two ligaments and their epiligaments. Our findings show a higher number of cells and a stronger expression of certain collagen types in the epiligament of the medial collateral compared to the anterior cruciate ligament, which may be related to the difference in their healing potential.

KEY WORDS: Anterior cruciate ligament; Medial collateral ligament; Epiligament; Collagen; Healing.

\section{INTRODUCTION}

The epiligament (EL) is a specialized tissue representing the outermost layer of the ligament, which was first described as 'any surrounding adherent connective tissue removed simultaneously with the ligament but which was grossly distinguishable from ligament tissue proper' (Bray et al., 1990). As opposed to the ligament, the EL contains multiple cellular structures, such as fibroblasts, fibrocytes and adipocytes (Georgiev et al., 2017). Moreover, there is an abundance of blood vessels and sensory/proprioceptive nerve elements in the EL, which form a complex network (Chowdhury et al., 1991). Structurally, the EL consists of collagen fibers, which, compared to those in the ligament proper, are smaller and oriented in various directions (Chowdhury et al.). The EL serves as a donor of fibroblasts, progenitor cells and blood vessels in the growth and repair processes of the ligament proper (Chowdhury et al.; Georgiev et al., 2010b; Georgiev et al., 2015b). EL fibroblasts synthetize a variety of molecules, such as collagen, fibronectin, decorin and matrix metalloproteinases (MMPs) which are essential for ligament remodeling (Chamberlain et al., 2011; Georgiev et al., 2010a, 2015a).

In contrast, the ligament proper contains fewer cellular and vascular structures (Hsu et al., 2010). The collagen fibers in the ligament proper are organized in fascicles, covered by a thin sheath of connective tissue, called endoligament (Georgiev et al., 2017a). Around $75 \%$ of the ligament proper's dry weight is represented by collagen, including collagen types

\footnotetext{
${ }^{1}$ Department of Anatomy, Histology and Embryology, Medical University of Sofia, Sofia, Bulgaria.

${ }^{2}$ Department of Orthopedics and Traumatology, University Hospital 'Queen Giovanna - ISUL', Medical University of Sofia, Sofia, Bulgaria.
} 
ILIEV, A.; KOTOV, G.; STAMENOV, N.; LANDZHOV, B.; KIRKOV, V. \& GEORGIEV, G. P. A comparative immunohistochemical and quantitative study of the epiligament of the medial collateral and anterior cruciate ligament in rat knee. Int. J. Morphol., 39(1):151-159, 2021.

I, III, V, VI, XI and XIV (Hauser et al., 2013). The main collagen type, representing $85 \%$ of the total collagen mass, is type I, which ensures the strength and endurance of ligaments (Hauser et al.). On the contrary, collagen fibrils in the EL are mainly composed of collagen types III and V (Chamberlain $e t$ al.; Georgiev et al., 2017b). Collagen type III has been shown to play an important role in ligament repair (Hsu et al.; Chamberlain et al.; Hauser et al.). Collagen type V, too, has been associated with ligament recovery and the intensity of its expression corresponds to the diameter of collagen fibrils (Niyibizi et al., 2000).

There is abundant evidence in the literature regarding the different healing potential of the anterior (cranial) cruciate ligament (ACL) and the medial collateral ligament (MCL) of the knee joint (Wijdicks et al., 2010; Andrews et al., 2017). A number of studies have suggested several explanations for this phenomenon. One of them describes the different ultrastructure of the connective tissue cells in the MCL and ACL (Lyon et al., 1991). Later studies found differences in the fibroblasts and their proliferative potential (Yoshida \& Fuji, 1999). Some scientists have suggested that the higher levels of nitric oxide produced by the ACL cells inhibit collagen and proteoglycan synthesis (Cao et al., 2000). Others noted a stronger blood flow and pronounced angiogenesis in the MCL after injury, followed by accelerated healing (Bray et al., 2003). Differences have also been reported in the expression of MMP-2, -9 and 13 (Georgiev et al., 2018; Nishikawa et al., 2018).

The aim of the present study was to evaluate the importance of the EL for the difference in the healing potential of the ACL and MCL. We conducted a comparative study of the EL structure in the two ligaments and traced the differences in the immunohistochemical expression of collagen types I, III and V in the EL and ligament proper in a rat knee model. In addition, we performed a comparative quantitative analysis of the number of cells per $\mathrm{mm}^{2}$ in both the EL and ligament proper of the ACL and MCL.

\section{MATERIAL AND METHOD}

For the present study, we used 10 knee joints, freshly obtained from five healthy 8-month-old male Wistar rats without any history of previous trauma available at the Department of Anatomy, Histology and Embryology at the Medical University of Sofia. All animal procedures conformed to the guidelines of Directive 2010/63/EU of the European Union. All experiments were conducted with the approval of the Medical Legal Office, the Local Ethics Committee and the University Committee on Animal Resources (No. 4866). All animals received humane care in compliance with the
'Principles of laboratory animal care' formulated by the National Society for Medical Research and the 'Guide for the care and use of laboratory animals' prepared by the National Institute of Health (NIH publication No. 86-23, revised 1996).

For the analysis, we used samples from the midsubstance of the MCL and the ACL of the knee joint. Small pieces of the EL and ligament proper of the MCL and ACL were immediately fixed in $10 \%$ neutral phosphate-buffered formalin solution for $24 \mathrm{~h}$ and were then dehydrated in increasing concentrations of ethanol $(70 \%, 80 \%, 95 \%, 100$ $\%)$. The samples were rinsed in xylene and embedded in paraffin. Sections were cut on a microtome at a thickness of 5 $\mu \mathrm{m}$.

For the immunohistochemical analysis, we used the following primary antibodies: mouse monoclonal anti-collagen type I IgG antibody (Santa Cruz Biotechnology Catalogue No. sc-293182, Santa Cruz Biotechnology Inc., Heidelberg, Germany); mouse monoclonal anti-collagen type III IgG antibody (Abcam Catalogue No. ab6310, Abcam, Cambridge, United Kingdom); mouse monoclonal anti-collagen type V IgG antibody (Santa Cruz Biotechnology Catalogue No. sc166155); all antibodies were used at concentration 1:500, all according to the standard procedure.

For semi-quantitative analysis of the expression of the collagen molecules, we used software ImageJ 1.52a, freely downloaded from the website of the National Institute of Health (NIH) (http://imagej.nih.gov/ij/). The intensity of staining was assessed through the IHC Profiler plugin, freely downloaded from the Sourceforge website (https:// sourceforge.net/projects/ihcprofiler/), according to the wellestablished protocol used in our previous studies (Georgiev $e t$ al., 2019). The IHC Profiler assigned a score to each visual field in a four tier system - high positive (3+), positive (2+), low positive (1+) and negative (0). Five slides were used from each ligament. We analyzed at least ten random visual fields on each slide. The final score was the average of the scores of all visual fields as calculated by the IHC Profiler.

For the quantitative analysis, we used ten randomly selected slides from each ligament. The EL and the ligament tissue proper were visualized on each slide. The slides were stained with hematoxylin and eosin according to standard methods. Quantitative data were obtained with a computerized system for image analysis NIS-Elements Advanced Research, Ver. 2.30. For a clearer representation of the obtained data, the number of cells was then calculated proportionally per surface area of $1 \mathrm{~mm}^{2}$. Statistica software was used for the statistical analysis. Our data were normally distributed which, together with the sufficient sample size, prompted us to use a parametric test - Student's T-test. 
ILIEV, A.; KOTOV, G.; STAMENOV, N.; LANDZHOV, B.; KIRKOV, V. \& GEORGIEV, G. P. A comparative immunohistochemical and quantitative study of the epiligament of the medial collateral and anterior cruciate ligament in rat knee. Int. J. Morphol., 39(1):151-159, 2021.

\section{RESULTS}

Normal structure of the EL of the MCL and ACL. The morphological appearance of the EL of the MCL and ACL was observed and compared to that of the ligament proper (Fig. 1-4). In the EL of both ligaments we found active fibroblasts with intensive nuclear staining. We also described fibrocytes, adipose cells and a multitude of neuro-vascular bundles. In addition, we observed multiple extracellular collagen fibers with uniformly small diameters, which had a somewhat random organization. Overall, the appearance of the EL was quite similar to that of the synovium. In contrast, the ligament proper in both the MCL and ACL was made up of fascicles of collagen fibers with parallel orientation. All fascicles appeared hypocellular, with a small number of cellular nuclei observed between the collagen fibers. We noted the presence of relatively few neuro-vascular bundles.

Expression of collagen types I, III and V in the EL and ligament proper of the MCL and ACL. In the MCL, immunostaining for collagen type I was observed ubiquitously in the EL and appeared especially strong in all layers of the walls of blood vessels (Fig. 1a,b). In the EL of the ACL,
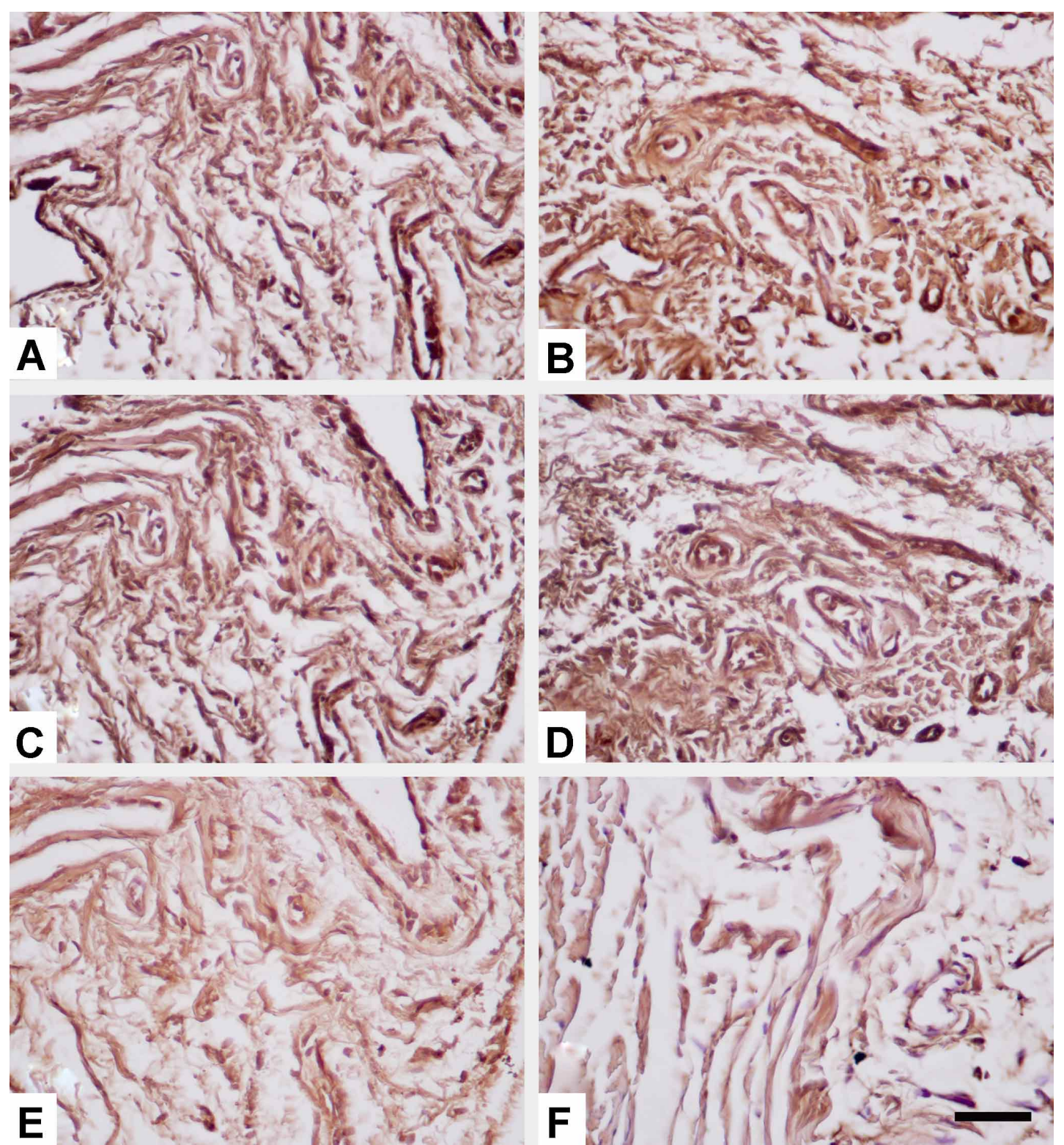

E

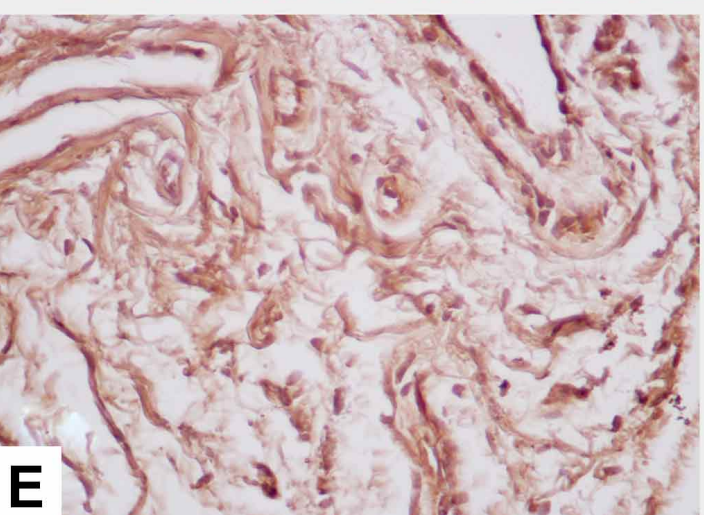

Fig. 1. Immunohistochemical expression of collagen types I, III and V in the epiligament of the medial collateral ligament in rat knee. Scale bar - 50 $\mu \mathrm{m}$. A, B - Immunohistochemical expression of collagen type I C, D Immunohistochemical expression of collagen type III. E, F - Immunohistochemical expression of collagen type V. 
ILIEV, A.; KOTOV, G.; STAMENOV, N.; LANDZHOV, B.; KIRKOV, V. \& GEORGIEV, G. P. A comparative immunohistochemical and quantitative study of the epiligament of the medial collateral and anterior cruciate ligament in rat knee. Int. J. Morphol., 39(1):151-159, 2021.

Table I. Semi-quantitative analysis of the immunohistochemical expression of collagen types I, III and V in the epiligament and ligament proper of the medial collateral and anterior cruciate ligament. The percentage for each score represents the percentage of visual fields that the IHC Profiler assigned this score to. MCL - medial collateral ligament; ACL - anterior cruciate ligament; EL - epiligament; L - ligament proper.

\begin{tabular}{|c|c|c|c|c|}
\hline \multirow{2}{*}{ Type of collagen } & \multicolumn{2}{|l|}{ MCL } & \multicolumn{2}{|l|}{ ACL } \\
\hline & EL & $\mathrm{L}$ & EL & $\mathrm{L}$ \\
\hline \multirow{4}{*}{ Collagen type I } & High-positive (3+) (6\%) & Positive $(2+)(22 \%)$ & Positive $(2+)(25 \%)$ & Positive $(2+)(27 \%)$ \\
\hline & Positive $(2+)(58 \%)$ & Low-positive (1+) & Low-positive $(1+)(56 \%)$ & Low-positive $(1+)(39 \%)$ \\
\hline & Low-positive $(1+)(19 \%)$ & Negative (0) $(36 \%)$ & Negative $(0)(19 \%)$ & Negative (0) $(34 \%)$ \\
\hline & Negative (0) $(17 \%)$ & & & \\
\hline \multirow{4}{*}{ Collagen type III } & High-positive $(3+)(56 \%)$ & Positive $(2+)(3 \%)$ & Positive $(2+)(49 \%)$ & Low-positive $(1+)(31 \%)$ \\
\hline & Positive $(2+)(22 \%)$ & Low-positive $(1+)$ & Low-positive $(1+)(30 \%)$ & Negative $(0)(69 \%)$ \\
\hline & Low-positive $(1+)(13 \%)$ & Negative (0) (47\%) & Negative $(0)(21 \%)$ & \\
\hline & Negative (0) $(9 \%)$ & & & \\
\hline \multirow{4}{*}{ Collagen type V } & High-positive $(3+)(39 \%)$ & Low-positive & Positive (1+) (44\%) & Low-positive $(1+)(17 \%)$ \\
\hline & Positive $(2+)(35 \%)$ & Negative (0) $(88 \%)$ & Low-positive (1+) (31\%) & Negative $(0)(83 \%)$ \\
\hline & Low-positive $(1+)(20 \%)$ & & Negative $(0)(25 \%)$ & \\
\hline & Negative $(0)(6 \%)$ & & & \\
\hline
\end{tabular}

collagen type I expression was noted in the adventitia of blood vessels (Fig. 2a,b). In both ligaments, staining appeared

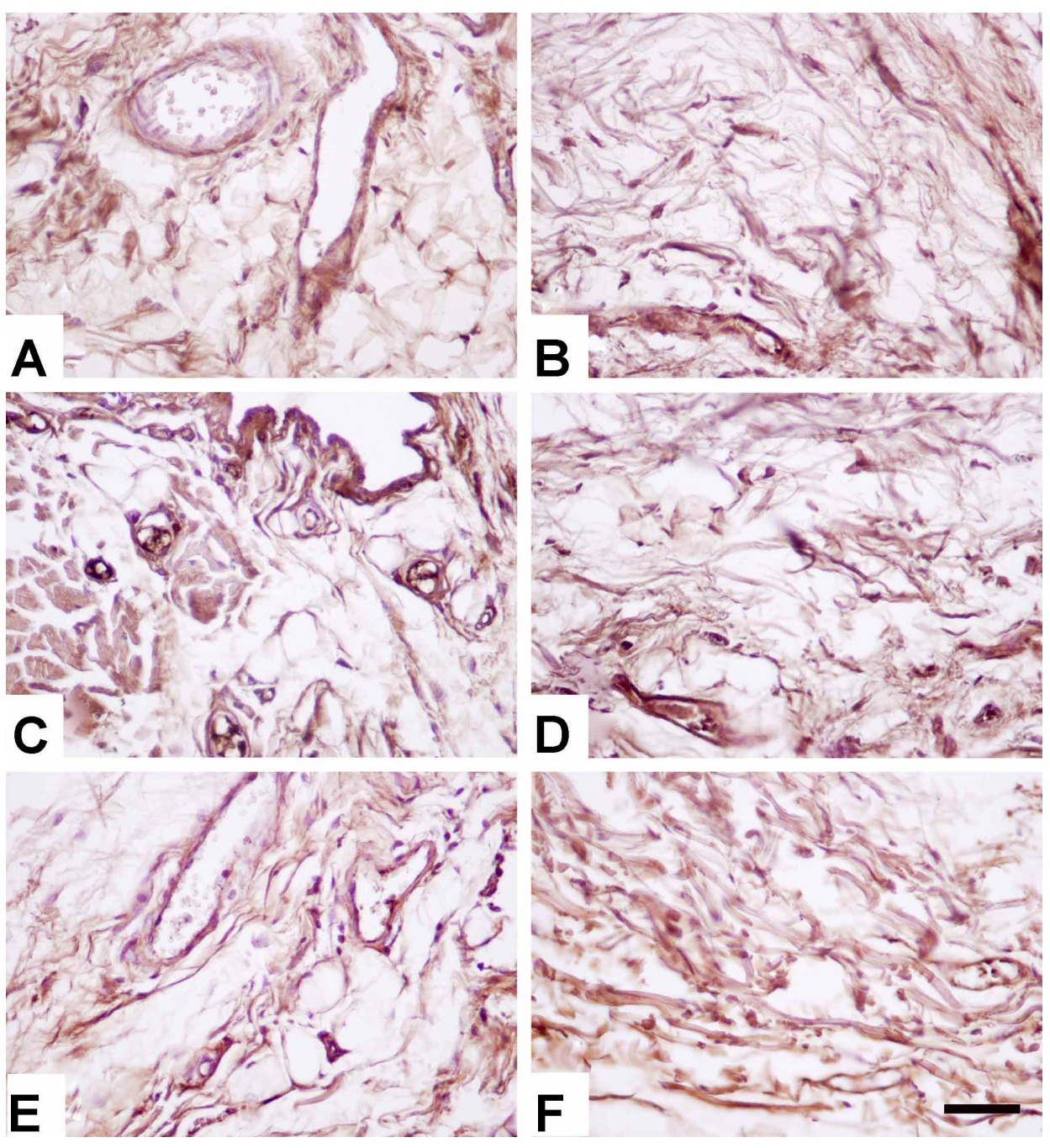

moderate throughout the ligament proper (Figs. 3a and 4a). In all layers of the walls of blood vessels and on the periphery
Fig. 2.Immunohistochemical expression of collagen types I, III and $\mathrm{V}$ in the epiligament of the anterior cruciate ligament in rat knee. Scale bar $-50 \mu \mathrm{m}$.

A, B - Immunohistochemical expression of collagen type I.

C, D - Immunohistochemical expression of collagen type III. $\mathrm{E}, \mathrm{F}$ - Immunohistochemical expression of collagen type $\mathrm{V}$. 
of adipocytes in the peripheral layer of the EL we detected immunoreactivity for collagen type III (Fig. 1c,d, 2c,d). Expression in the ligament proper of both ligaments appeared low to absent (Figs. 3b, 4b). The immunohistochemical reaction for collagen type $\mathrm{V}$ was observed mostly in the adventitia of blood vessels and in the superficial layer of the
EL in both ligaments (Figs. 1e, 1f, 2e and 2f). Expression in the ligament proper of both ligaments appeared low to absent (Figs. 3c and 4c). We conducted a semi-quantitative analysis with the IHC Profiler in order to determine the variation in the intensity of immunostaining between the EL and ligament proper of the MCL and ACL. Results are shown in Table I.
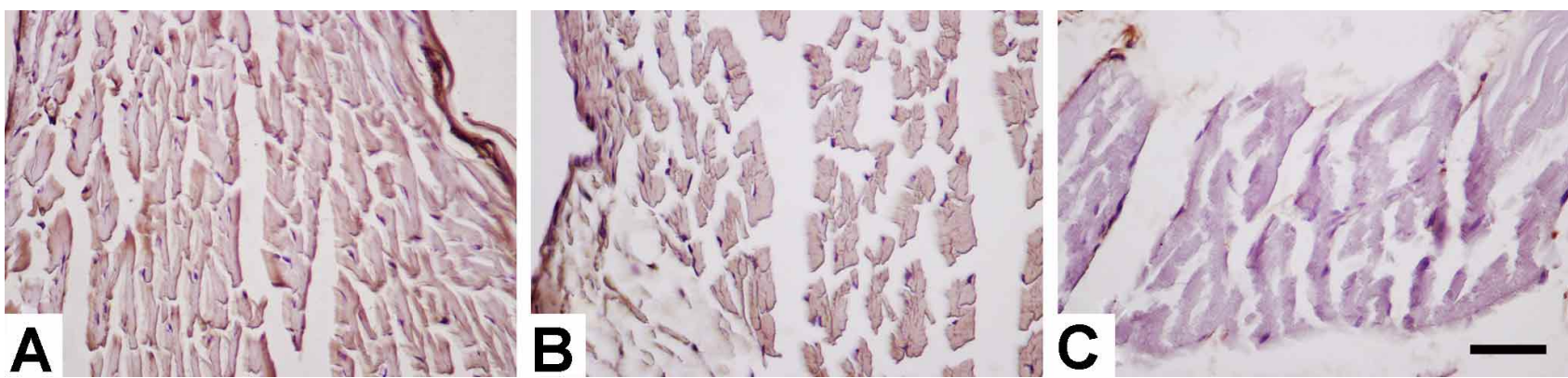

Fig. 3. Immunohistochemical expression of collagen types I, III and V in the ligament proper of the medial collateral ligament in rat knee. Scale bar - $50 \mu \mathrm{m}$. A - Immunohistochemical expression of collagen type I. B - Immunohistochemical expression of collagen type III. C Immunohistochemical expression of collagen type $\mathrm{V}$
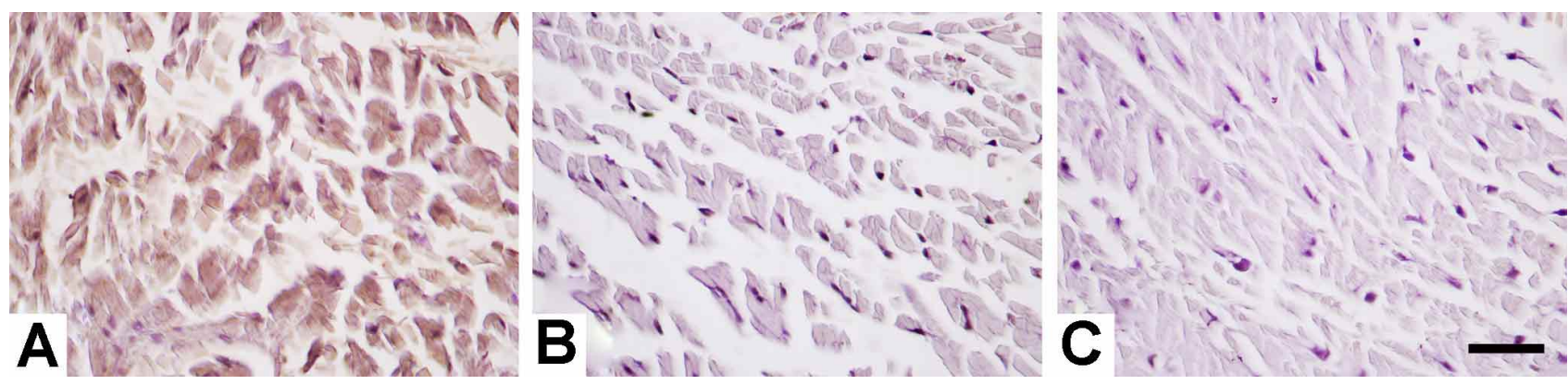

Fig. 4. Immunohistochemical expression of collagen type I, III and V in the ligament proper of the anterior cruciate ligament in rat knee. Scale bar $-50 \mu \mathrm{m}$. A - Immunohistochemical expression of collagen type I. B - Immunohistochemical expression of collagen type III. C Immunohistochemical expression of collagen type $\mathrm{V}$.
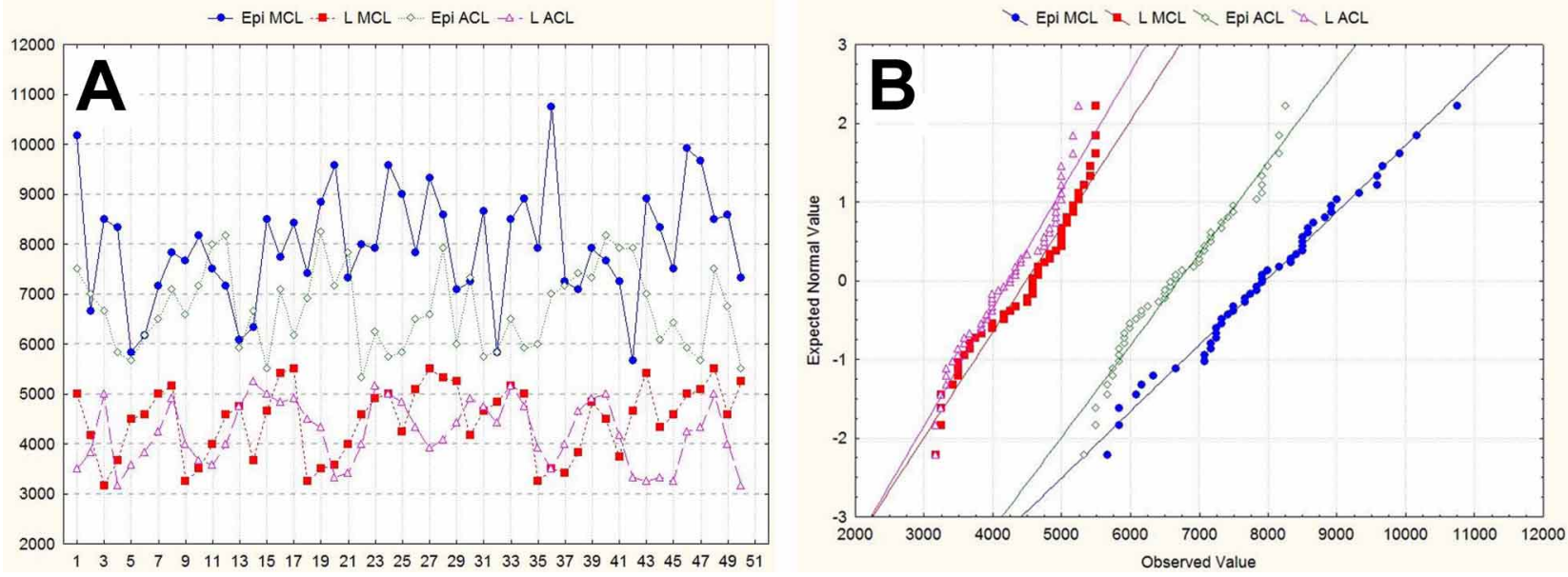

Fig. 5. A diagram showing the range of the obtained values for number of cells per $\mathrm{mm}^{2}$ in the epiligament and ligament proper of the medial collateral and anterior cruciate ligament in rat knee. MCL - medial collateral ligament; ACL anterior cruciate ligament; Epi - epiligament; L - ligament proper. A - Line plot. $\mathrm{x}$-axis - number of measurements; yaxis - obtained values. B - Normal probability plot. 
Quantitative analysis. We analyzed the number of cells per area of $0.012 \mathrm{~mm}^{2}$ in 50 areas in both the EL and the ligament proper of each ligament and then calculated it proportionally per area of $1 \mathrm{~mm}^{2}$. The obtained values for the parameter number of cells were visualized with diagrams (Fig. 5). The mean and median values and the standard deviation were calculated and are presented in Table II. Box and whisker plots were created for visual representation of the difference in the mean and median values (Fig. 6). The difference in the number of cells per $\mathrm{mm}^{2}$ in the two substructures of the two ligaments was then tested with Student's T-test. Statistically significant difference $(\mathrm{p}<0.05)$ was reported between the mean values for number of cells per $\mathrm{mm}^{2}$ between the EL of the MCL and that of the ACL. Conversely, the analysis of the difference between the values in the ligament proper yielded $\mathrm{p}>0.05$ and the reported difference was deemed not to be statistically significant (Table III).

Table II. Descriptive statistics of the quantitative data for the number of cells per $\mathrm{mm}^{2}$ in the medial collateral and anterior cruciate ligament. $\mathrm{MCL}$ - medial collateral ligament; ACL - anterior cruciate ligament; Epi - epiligament; L ligament proper; SD - standard deviation.

\begin{tabular}{lllll}
\hline & Epi MCL & L MCL & Epi ACL & L ACL \\
\hline MEAN case 1-50 & 7963.33 & 4483.33 & 6701.67 & 4230 \\
MEDIAN case 1-50 & 7916.67 & 4583.33 & 6625 & 4250 \\
SD case 1-50 & 1148.44 & 708.11 & 822.22 & 636.11 \\
MIN case 1-50 & 5667 & 3167 & 5333 & 3167 \\
MAX case 1-50 & 10750 & 5500 & 8250 & 5250 \\
_25th\% case 1-50 & 7250 & 3833.33 & 5916.67 & 3666.67 \\
-75th\% case 1-50 & 8583.33 & 5000 & 7333.33 & 4833.33 \\
\hline
\end{tabular}

Table III. Statistical evaluation of the difference between the means of the number of cells per mm2 obtained in the epiligament and ligament proper of the medial collateral and anterior cruciate ligament. MCL - medial collateral ligament; ACL - anterior cruciate ligament; Epi - epiligament; L - ligament proper; SD - standard deviation.

\begin{tabular}{lllllll}
\hline & Mean & Mean & Mean Group 1 - & \multirow{2}{*}{ SD1 } & SD2 & p-value \\
& Group 1 & Group 2 & Mean Group 2 & & & \\
\hline Epi MCL vs. Epi ACL & 7963.33 & 6701.67 & 1261.66 & 1148.44 & 822.22 & 0.000 \\
L MCL vs. L ACL & 4483.33 & 4230 & 253.33 & 708.11 & 636.11 & 0.063 \\
\hline
\end{tabular}
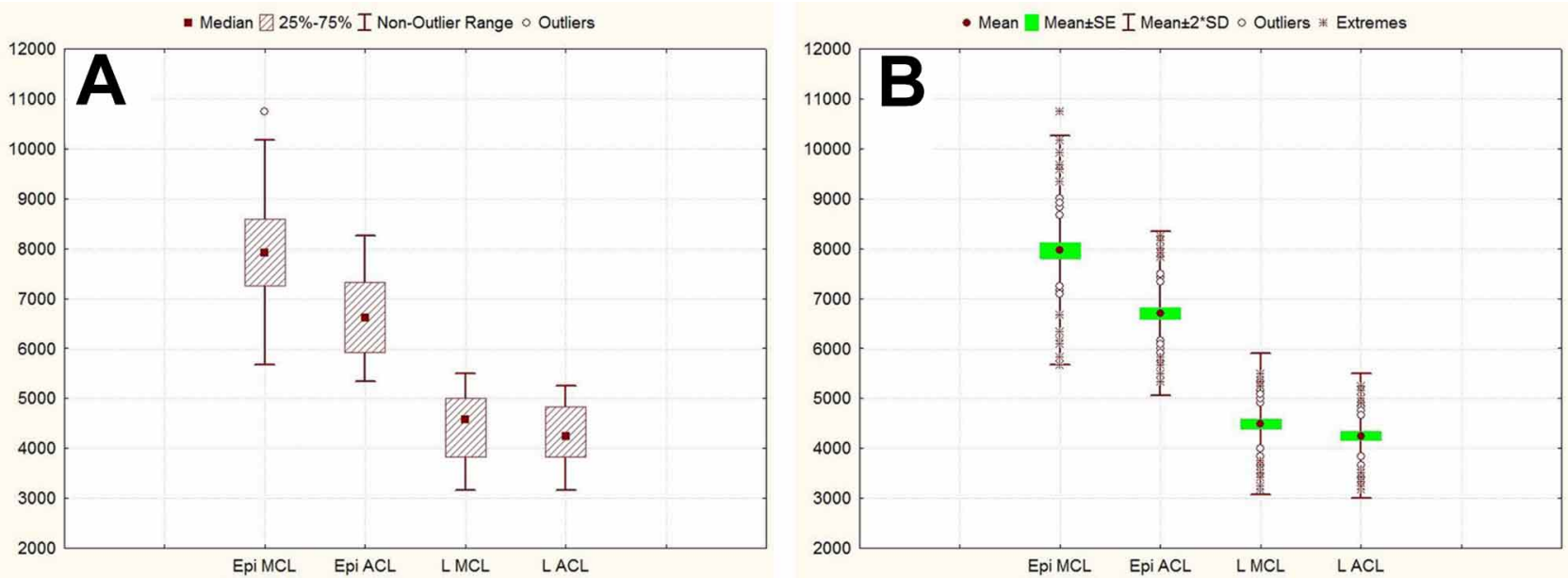

Fig. 6. Graphical representation of the descriptive statistics of the quantitative data for the number of cells in the anterior cruciate and medial collateral ligament. MCL - medial collateral ligament; ACL - anterior cruciate ligament; Epi - epiligament; L - ligament proper. A - Box and whisker plots showing the median (square), surrounded by a 'box', the vertical edge of which is the interval between the lower and upper quartile [25 \%-75\%]. 'Whiskers' originating from this 'box' represent the non-outlier range. Circles - outliers. B - Box and whisker plots showing the mean (dot), surrounded by a 'box', the vertical edge of which is the interval [Mean-SE, Mean+SE]. 'Whiskers' originating from this 'box' represent the 2-sigma confidence interval of the mean, i.e. [Mean- $2 * \mathrm{SD}$, Mean $+2 * \mathrm{SD}$ ]. Circles - outliers; SE - standard error of mean; SD - standard deviation. 


\section{DISCUSSION}

In our study, we examined the differences in the expression of collagen types I, III and V in the EL and ligament proper of the MCL and ACL in rat knee, while also evaluating the intensity of immunostaining semi-quantitatively. In addition, we performed a comparative quantitative analysis of the number of cells per $\mathrm{mm}^{2}$ in the EL and ligament proper of the two ligaments and assessed whether a statistically significant difference existed. We have thus presented one of the very first comparative studies of collagen expression in the EL in a rat model, as well as the potential significance of the abundant number of cells for the properties of the EL of the MCL and ACL.

The most abundant extracellular component of soft connective tissue and its major tensile-bearing element is collagen (Georgiev et al., 2010; Wan et al., 2013; Georgiev et al., 2015b). The main collagen type found in the ligament is type I and it is chiefly responsible for its tensile strength (Georgiev et al., 2010, 2015b). Under physiological conditions, the expression of collagen types III and V is low, yet their synthesis is significantly increased after injury (Georgiev et al., 2010; Wan et al.; Georgiev et al., 2015a,b). In previous reports, the role of collagen type III for proper ligament recovery has been discussed (Niyibizi et al.; Georgiev et al., 2010a; Hsu et al.; Georgiev et al., 2019). Its synthesis rapidly increases in the first stages of ligament healing and during the ligamentization after tendon graft, surpassing the levels of type I. Its values return to normal by 52 weeks after injury (Niyibizi et al.; Hsu et al.). Herein, we have shown that the expression of collagen type III is predominantly observed in the EL of both the MCL and ACL, supplying further evidence of the role of the EL in ligament recovery. Hauser et al. found that after injury, fibroblasts mainly synthetize collagen type III. Considering the high number of fibroblasts in the EL, it would be reasonable to suggest that they are chiefly responsible for the upregulated collagen type III. On the other hand, collagen type $\mathrm{V}$, has been shown to participate in the organization and regulation of collagen type I fibril diameters (Breuls et al., 2009; Georgiev et al., 2010b, 2015a,b). Collagen type V is responsible for cell morphology, protein synthesis, growth kinetics and migration during tissue development, as well as inflammation and wound repair (Breuls et al.; Georgiev et al., 2010b, 2015a,b). Breuls et al. reported that type V collagen fibrils participate in the regulation of modeling and remodeling of the extracellular matrix by controlling collagen fibril initiation. A low-positive immunoreactivity of collagen type $\mathrm{V}$ was reported on the 8th and 16th day after grade III injury of the collateral ligaments of the knee in a rat model and similar to normal levels were seen on the 30th day (Georgiev et al., 2010a,b, 2015a). In our study, the immunohistochemical reaction for collagen type III and type V was similar and observed predominantly in the EL tissue of the two ligaments.

The difference in the healing potential of the MCL and ACL has been well documented in the literature (Wijdicks et al.; Andrews et al.). Multiple theories have been suggested in an attempt to understand this difference. One of them points to the fact that the ACL has an intra-articular location and is exposed to the impact of synovial fluid which has an inhibitory effect on the function of fibroblasts (Andrish \& Holmes, 1979). Vavken \& Murray (2011) suggested that plasmin circulating in the synovial fluid may slow healing by breaking down the fibrin clot. Moreover, the intra-articular environment decreases the size of the wound site, meaning that cells and blood vessels are less likely to bridge the gap between the ligament's ruptured ends in a proper way (Chen, 2009). While this theory provides a plausible explanation for the poor healing capacity of the ACL, we have herein shown the possible significance of the EL. The EL is important for the healing process by delivering fibroblasts to the site of injury. Our study shows a statistically significant difference in the number of fibroblasts per $\mathrm{mm}^{2}$ in the EL of ACL and MCL in favor of the MCL. Secondly, we have confirmed that fibroblasts in the EL are not static cells but instead actively produce different types of collagen. Therefore, the lower expression of collagen types associated with ligament recovery such as collagen types III and V in the EL of the ACL as evaluated by our semi-quantitative analysis provides another explanation for the poorer healing capacity of the ACL. On the other hand, the MCL has been repeatedly shown to heal spontaneously after rupture (Wijdicks et al.; Andrews et al.).

\section{Limitations of the current study existed and should be}

noted. First, the comparison of the morphological organization of the EL in the two studied ligaments on histological slides routinely stained with hematoxylin and eosin was of somewhat descriptive nature. In order to provide objective data and eliminate researcher bias, we conducted a comparative quantitative analysis of the number of connective tissue cells per $\mathrm{mm}^{2}$ in the two sub-structures of the ligament - EL and ligament proper. Secondly, the histological preparation of the slides resulted in tissue ruptures and limited the regions of interest in the EL and ligament proper which could be investigated. Third, the visual quantification of immunohistochemical images is generally associated with significant inter- and intra-observer variation. We attempted to resolve this issue by using the IHC Profiler plugin for the ImageJ software, which eliminates inter-observer visual perception bias.

In conclusion, our study confirms that the EL of the $\mathrm{MCL}$ and the ACL is quite different from the ligament proper. It contains an abundance of fibroblasts, fibrocytes and 
adipocytes, as well as neuro-vascular bundles. EL fibroblasts are not static cells and produce varying quantities of collagen types I, III and V. The immunohistochemical expression of the studied collagen types was stronger in the EL than in the ligament proper and was higher in the EL of the MCL as opposed to the ACL. In addition, we reported a statistically significant difference between the number of cells per $\mathrm{mm}^{2}$ in the EL of the two ligaments, which was higher in the MCL. Thus, we have presented new data on the structural and functional significance of the EL tissue, which suggest that it may be responsible for the better healing capacity of the MCL in comparison to the ACL.

\section{ACKNOWLEDGEMENTS}

The authors would like to express their most sincere gratitude to Assoc. Prof. Jordanka A. Angelova, PhD, of the University of Chemical Technology and Metallurgy, Sofia, Bulgaria for her valuable assistance in the preparation of the statistical analysis.

ILIEV, A.; KOTOV, G.; STAMENOV, N.; LANDZHOV, B.; KIRKOV, V. \& GEORGIEV, G. P. Estudio inmunohistoquímico y cuantitativo del epiligamento del ligamento colateral medial y cruzado anterior en rodilla de rata. Int. J. Morphol., 39 (1):151-159, 2021.

RESUMEN: El objetivo del presente estudio fue evaluar la importancia del epiligamento para la diferencia en el potencial de curación del ligamento cruzado anterior y colateral medial de la rodilla. Comparamos la estructura del ligamento cruzado anterior y el ligamento colateral medial y evaluamos las diferencias en la expresión de los tipos de colágeno I, III y V en una rodilla de rata. También se realizó un análisis cuantitativo comparativo del número de células por $\mathrm{mm}^{2}$ en los dos ligamentos. Se obtuvieron muestras de tejido del ligamento cruzado anterior y colateral medial de 10 articulaciones de rodilla tomadas de cinco ratas Wistar de 8 meses de edad. Utilizamos tinción estándar con hematoxilina y eosina, además de tinción inmunohistoquímica con anticuerpos monoclonales contra colágeno tipo I, III y V. Se realizó un análisis semicuantitativo de la expresión mediante ImageJ, mientras que para el análisis estadístico se utilizó la prueba T de Student. Nuestros resultados mostraron una mayor expresión de todos los tipos de colágeno en el epiligamento, en comparación con el ligamento y una diferencia en la expresión entre el ligamento colateral medial y el ligamento cruzado anterior. También informamos una diferencia estadísticamente significativa en el número de células por $\mathrm{mm}^{2}$ entre los dos ligamentos y sus epiligamentos. Nuestros hallazgos muestran un mayor número de células y una expresión mayor de ciertos tipos de colágeno en el epiligamento colateral medial en comparación con el ligamento cruzado anterior, lo que puede estar relacionado con la diferencia en su potencial de curación.

PALABRAS CLAVE: Ligamento cruzado anterior; Ligamento colateral medio; Epiligamento; Colágeno; Curación.

\section{REFERENCES}

Andrews, K.; Lu, A.; Mckean, L. \& Ebraheim, N. Review: medial collateral ligament injuries. J. Orthop., 14(4):550-4, 2017.

Andrish, J. \& Holmes, R. Effects of synovial fluid on fibroblasts in tissue culture. Clin. Orthop. Relat. Res., (138):279-83, 1979.

Bray, R. C.; Fisher, A. W. \& Frank, C. B. Fine vascular anatomy of adult rabbit knee ligaments. J. Anat., 172:69-79, 1990.

Bray, R. C.; Leonard, C. A. \& Salo, P. T. Correlation of healing capacity with vascular response in the anterior cruciate and medial collateral ligaments of the rabbit. J. Orthop. Res., 21(16):1118-23, 2003.

Breuls, R. G. M.; Klumpers, D. D.; Everts, V. \& Smit, T. H. Collagen type V modulates fibroblast behavior dependent on substrate stiffness. Biochem. Biophys. Res. Commun., 380(2):425-9, 2009.

Cao, M.; Stefanovic-Racic, M.; Georgescu, H. I.; Fu, F. H. \& Evans, C. H. Does nitric oxide help explain the differential healing capacity of the anterior cruciate, posterior cruciate, and medial collateral ligaments? Am. J. Sports Med., 28(2):176-82, 2000.

Chamberlain, C. S.; Crowley, E. M.; Kobayashi, H.; Eliceiri, K. W. \& Vanderby, R. Quantification of collagen organization and extracellular matrix factors within the healing ligament. Microsc. Microanal., 17(5):779-87, 2011

Chen, C. H. Graft healing in anterior cruciate ligament reconstruction. Sports Med. Arthrosc. Rehabil. Ther. Technol., 1:21, 2009.

Chowdhury, P.; Matyas, J. R. \& Frank, C. B. The "epiligament" of the rabbit medial collateral ligament: a quantitative morphological study. Connect. Tissue Res., 27(1):33-50, 1991

Georgiev, G. P.; Iliev, A.; Kotov, G.; Kinov, P.; Slavchev, S. \& Landzhov, B. Light and electron microscopic study of the medial collateral ligament epiligament tissue in human knees. Wolrd J. Orthop., 8(5):372-8, $2017 \mathrm{a}$.

Georgiev, G. P.; Kinov, P.; Rashev, P.; Sapundzhiev, E. \& Vidinov, N. K. Changes in the distribution of fibrillar collagens during early healing of the lateral collateral ligament epiligament tissue in rat knee model. Compt. Rend. Acad. Bulg. Sci., 63(5):761-6, 2010a.

Georgiev, G. P.; Kotov, G.; Iliev, A.; Slavchev, S.; Ovtscharoff, W. \& Landzhov, B. A comparative study of the epiligament of the medial collateral and the anterior cruciate ligament in the human knee. Immunohistochemical analysis of collagen type I and $\mathrm{V}$ and procollagen type III. Ann. Anat., 224:88-96, 2019.

Georgiev, G. P.; Landzhov, B.; Dimitrova, I. N.; Slavchev, S.; Malinova, L. \& Kartelov, Y. Light microscopic and immunohistochemical study of the medial collateral ligament epiligament in rat knee. Compt. Rend. Acad. Bulg. Sci., 68(1):95-100, 2015 b.

Georgiev, G. P.; Landzhov, B.; Dimitrova, I. N.; Slavchev, S.; Malinova, L. \& Ovtscharoff, W. Immunohistochemical study during early healing of the medial collateral ligament epiligament in rat knee model. Compt. Rend. Acad. Bulg. Sci., 68(5):655-60, 2015a.

Georgiev, G. P.; Landzhov, B.; Kotov, G.; Slavchev, S. A. \& Iliev, A. Matrix metalloproteinase-2 and -9 expression in the epiligament of the medial collateral and anterior cruciate ligament in human knees: a comparative study. Cureus, 10(11):e3550, 2018.

Georgiev, G. P.; Vidinov, N. K. \& Kinov, P. S. Histological and ultrastructural evaluation of the early healing of the lateral collateral ligament epiligament tissue in a rat knee model. BMC Musculoskelet. Disord., 11:117, 2010b.

Hauser, R. A.; Dolan, E. E.; Phillips, H. J.; Newlin, A. C.; Moore, R. E. \& Woldin, B. A. Ligament injury and healing: a review of current clinical diagnostics and therapeutics. Open Rehabil. J., 6:1-20, 2013.

Hsu, S. L.; Liang, R. \& Woo, S. L. Functional tissue engineering of ligament healing. Sports Med. Arthrosc. Rehabil. Ther. Technol., 2:12, 2010.

Lyon, R. M.; Akeson, W. H.; Amiel, D.; Kitabayashi, L. R. \& Woo, S. L. Ultrastructural differences between the cells of the medical collateral and the anterior cruciate ligaments. Clin. Orthop. Relat. Res., (272):279$86,1991$. 
Nishikawa, Y.; Kokubun, T.; Kanemura, N.; Takahashi, T.; Matsumoto, M.; Maruyama, H. \& Takayanagi, K. Effects of controlled abnormal joint movement on the molecular biological response in intra-articular tissues during the acute phase of anterior cruciate ligament injury in a rat model. BMC Musculoskelet. Disord., 19:175, 2018.

Niyibizi, C.; Kavalkovich, K.; Yamaji, T. \& Woo, S. L. Type V collagen is increased during rabbit medial collateral ligament healing. Knee Surg. Sports Traumatol. Arthrosc., 8(5):281-5, 2000.

Vavken, P. \& Murray, M. M. The potential for primary repair of the ACL. Sports Med. Arthrosc., 19(1):44-9, 2011.

Wan, C.; Hao, Z. \& Wen, S. A quantitative comparison of morphological and histological characteristics of collagen in the rabbit medial collateral ligament. Ann. Anat., 195(6):562-9, 2013.

Wijdicks, C. A.; Griffith, C. J.; Johansen, S.; Engebretsen, L. \& LaPrade, R. $\mathrm{F}$. Injuries to the medial collateral ligament and associated medial structures of the knee. J. Bone Joint Surg., 92(5):1266-80, 2010.

Yoshida, M. \& Fujii, K. Differences in cellular properties and responses to growth factors between human ACL and MCL cells. J. Orthop. Sci., 4(4):293-8, 1999
Corresponding author:

Georgi Kotov, MD

Department of Anatomy, Histology and Embryology

Medical University of Sofia

2 Zdrave St.

BG 1431 Sofia

BULGARIA

Email: gn_kotov@abv.bg

Received: 31-08-2020

Accepted: 21-09-2020 